\title{
Computer decision support changes physician practice but not know- ledge regarding autism spectrum disorders
}

\author{
N.S. Bauer ${ }^{1,3} ;$ A.E. Carroll ${ }^{2,3}$; C. Saha ${ }^{4}$; S.M. Downs ${ }^{1,3}$ \\ ${ }^{1}$ Indiana University School of Medicine, Department of Pediatrics, Section of Children's Health Services Research, Indianapolis, In- \\ diana, USA; ${ }^{2}$ Indiana University School of Medicine, Department of Pediatrics, Section of Pediatric and Adolescent Comparative \\ Effectiveness Research, Indianapolis, Indiana, USA; ${ }^{3}$ Regenstrief Institute for Healthcare, Indianapolis, Indiana, USA; \\ ${ }^{4}$ Indiana University School of Medicine, Department of Biostatistics
}

\section{Keywords}

computer-based decision support, pediatrics, clinical guidelines, autism spectrum disorder, primary care, screening

\section{Summary}

Objective: To examine whether adding an autism module promoting adherence to clinical guidelines to an existing computer decision support system (CDSS) changed physician knowledge and self-reported clinical practice.

Methods: The CHICA (Child Health Improvement through Computer Automation) system, a CDSS, was enhanced with a module to improve management of autism in 2 of the 4 community pediatric clinics using the system. We examined the knowledge and beliefs of pediatric users using cross-sectional surveys administered at 3 time points (baseline, 12 months and 24 months post-implementation) between November 2010 and January 2013. Surveys measured knowledge, beliefs and selfreported practice patterns related to autism.

Results: A total of 45,39 , and 42 pediatricians responded at each time point, respectively, a $95-100 \%$ response rate. Respondents' knowledge of autism and perception of role for diagnosis did not vary between control and intervention groups either at baseline or any of the two post-intervention time points. At baseline, there was no difference between these groups in rates in the routine use of parent-rated screening instruments for autism. However, by 12 and 24 months postimplementation there was a significant difference between intervention and control clinics in terms of the intervention clinics consistently screening eligible patients with a validated autism tool. Physicians at all clinics reported ongoing challenges to community resources for further work-up and treatment related to autism.

Conclusions: A CDSS module to improve primary care management of ASD in pediatric practice led to significant improvements in physician-reported use of validated screening tools to screen for ASDs. However it did not lead to corresponding changes in physician knowledge or attitudes.

\section{Correspondence to:}

Nerissa S. Bauer, MD, MPH

410 W. 10th Street, Suite 1000,

Indianapolis, IN 46202

Tel.: 317-278-0552

Email: nsbauer@iu.edu

\author{
Appl Clin Inform 2015; 6: 454-465 \\ http://dx.doi.org/10.4338/ACl-2014-09-RA-0084 \\ received: February 9, 2015 \\ accepted in revised form: June 8, 2015 \\ published: July 15, 2015 \\ Citation: Bauer NS, Carroll AE, Saha C, Downs SM. \\ Computer decision support changes physician practice \\ but not knowledge regarding autism spectrum dis- \\ orders. Appl Clin Inform 2015; 6: 454-465 \\ http://dx.doi.org/10.4338/ACl-2014-09-RA-0084
}




\section{Introduction}

The prevalence of autism spectrum disorders (ASD) is increasing and is a public health concern [1]. Primary care physicians play a central role in the early identification of ASDs as they are often the first providers to whom parents disclose concerns. However, the timely identification of ASD continues to be a challenge, particularly in the setting of a busy outpatient clinic [2]. Among families with children later found to be on the ASD spectrum, parents often started having concerns about their children's development within the first year of life. However, the national average for a confirmed diagnosis of an ASD is 4.5 years [3,4].

Tools exist to help primary care physicians identify ASDs in practice. These include clinical care guidelines $[5,6]$ and a brief, validated screening tool that can identify risk of autism as early as 18 months of age.[7] However, despite the existence of these tools, physicians find it hard to integrate these processes along with anticipatory guidance and other competing guidelines for routine surveillance and screening into the high volume and clinical flow of outpatient pediatric practice $[8,9]$. While these efforts have been increasing since clinical care guidelines were published in 2001 and 2007 and scientific discoveries have accelerated what is known about ASDs, $[5,6]$ the rate of autism screening among community physicians has remained relatively unchanged over the last 5 years [10, $11]$.

At our institution, we have developed a computer decision support system (CDSS) called the Child Health Improvement through Computer Automation system (CHICA), to support primary pediatric care. In 2009, we added a module to CHICA to automate surveillance and screening for ASDs. Health information technology (HIT) such as CHICA can facilitate and support healthcare delivery at the point of care, improve physicians' decision-making and help prevent medical errors [12]. Indeed, previous work done by our group has shown CHICA's effectiveness in improving physicians' adherence to clinical practice guidelines for ADHD, smoking cessation, maternal depression and developmental screening [13-17].

Little is known, however, about what impact CDSS has on physician knowledge or attitudes. One way to assess changes in screening practices is to measure self-reported knowledge and beliefs of physicians related to screening practices for ASD. The primary objective of this study was to examine whether exposure to automation of screening and ASD-specific physician reminders and prompts would lead to measurable changes in physicians' knowledge and attitudes regarding autism screening. Based on our anecdotal observations we hypothesized it would improve their knowledge and attitudes about their role in the screening and management of ASD because CHICA delivers advice at the point of care, a much recognized "teachable moment". Furthermore, we hypothesized that use of a CDSS for ASD screening would improve physician reported adherence to screening guidelines. To test this hypothesis, we surveyed physicians in the control and intervention clinics at baseline and over two time points after implementing the intervention.

\section{Methods}

\subsection{Overview of the Autism Screening Module of the CHICA System}

CHICA is a CDSS and electronic health record (EHR) that is operational in 4 community pediatric clinics in CHICA. CHICA has been described in detail elsewhere,[18-21] but briefly, this system was designed to automate various aspects of preventive care and chronic disease management and work within the busy workflow of pediatric practice. The CHICA system was developed on an open-source electronic medical record framework (www.openmrs.org), which is HL7-compliant and allows CHICA to link to an EHR [22]. CHICA produces two scannable and tailored paper forms, a pre-screener form (PSF) and a physician worksheet (PWS). On the PSF, CHICA prints a set of 20 health risk questions selected by the computer based on information in the child's EHR and the age of the child at the visit. The parent (or child if older than 12 years) completes the PSF in the waiting room prior to seeing the physician. See $>$ Figure 1 for a sample PSF form. The PSF is scanned into CHICA by a medical assistant prior to the encounter. The second scannable document, the PWS, is then generated. It contains a space for the physician to record notes and includes 6 prompts 
to guide decision-making at the point of care. CHICA selects these prompts based on the information obtained from the PSF and data in the EHR. See $>$ Figure 2 for a sample PWS that includes an autism-specific prompt.

In 2009, CHICA was enhanced with an autism module that included a set of autism-specific PSF questions, physician prompts, and Just-in-Time handouts (JITs) to supplement physician counseling [23]. When a child 22-26 months of age is seen in the clinic, the system adds questions to the PSF about autism risk and generates a scannable version of a validated screening tool, the Modified Checklist for Autism in Toddlers (M-CHAT), [7] to identify at-risk children in need of further work-up. The M-CHAT is completed by the family in the waiting room, and scanned into CHICA. CHICA scores the M-CHAT and prints a report with an interpretation for the physician, along with follow-up interview questions based on concerning responses [24-26]. CHICA generates autismspecific JITs, as well, for the physician to share with the family should the screening be positive. For children who have a confirmed diagnosis of an ASD, additional educational JITs covering various aspects pertinent to ongoing management (for example, behavior problems, parent and financial resources, complementary and alternative medicine) are generated at subsequent visits based on parental concerns recorded on the PSF. Prior to implementation of the module, the intervention clinics were informed that the ASD was developed and study personnel provided a brief overview of the module, associated PSF and PWS prompts and handouts. This standardized process is employed before the launch of new CHICA modules so that physicians and clinic staff are aware of major changes prior to implementation. Because every module is designed to work within the existing structure of CHICA, providers did not need additional in-depth training.

\subsection{Setting and Participants}

This study took place between November 2010 and January 2013. Data from this study are part of a larger cluster randomized controlled trial, in which 2 of the 4 clinics using CHICA were randomly assigned to receive the ASD module. The remaining two clinics were categorized as control sites as they had access to the CHICA system but not the ASD module. The decision to randomize at the clinic level was made to avoid potential contamination. When randomized at the provider level, providers in the same clinic assigned to different study conditions tend to communicate and share resources generated from CHICA. When randomized at the patient level, the intermittent printing of forms for some patients and not others leads staff at the clinic to believe CHICA was malfunctioning. Also, there is essentially no movement of the physicians between the four clinic sites and thus no risk of contamination due to physicians practicing in multiple clinics. For the present study, to understand whether the ASD module was associated with any change in physician knowledge about ASD or change in practice, physicians at all 4 clinics were asked to complete a survey on autism knowledge and practice. The four clinics are part of the Eskenazi Health System in Indianapolis, Indiana. These clinics serve a large proportion of families that are uninsured and underserved. Families served by these clinics are typically 58\% black, 30\% Latino, 25\% Spanish speaking, and 80\% on Medicaid. Data used in the present study represent a repeated cross-sectional study design embedded within a larger cluster randomized controlled trial.

\subsection{Data Collection and Analysis}

Physicians were asked to complete an adapted survey, [27] which was designed to capture physicians' knowledge about autism, perceptions of their role in the diagnosis and treatment of ASD, and physician demographics. The survey was administered at three time points (at baseline prior to implementation, 12 months post-implementation and again at 24 months post-implementation). The survey contained three domains: knowledge (20 items), attitudes towards diagnosis and treatment (4 items), and physician demographics (6 items). Physicians were asked to rate their agreement with ASD knowledge items (for example, autism is more frequently diagnosed in males than in females), using a 6-point rating scale ( $1=$ fully agree to $6=$ fully disagree). They were also asked to categorize their perceived role in establishing the diagnosis of autism, their typical use of parent-completed screening instruments when considering a diagnosis of autism in children aged 0 to 5 years, and their perceived role in the management of children with autism. Demographics included physician 
gender, years in practice excluding residency, primary specialty, and the approximate number of children 18 years and younger seen per week. See Supplementary Material for the full survey instrument.

Data were entered into a Microsoft excel database (Microsoft Corp, Redmond, WA) and then analyzed in SAS software version 9.3. We used double data entry whereby, two independent trained research assistants manually entered data into the database separately. Any discrepancies in entry were resolved by going back to the original paper copy of the data collection tool. This method was used to avoid data entry errors. Each survey administration was examined as separate cross-sectional samples since data were collected anonymously and could not be linked across time points. In addition having only two clusters per group and only three to five physicians surveyed in one clinic, intra cluster correlation issue could not be considered in the data analyses.

While the knowledge items asked physicians to provide ratings on a 6-point Likert scale, some of the cell frequencies were zero and the sample size by treatment group small. Therefore, knowledge item responses were collapsed from the 6-point scale to a binary variable (agree or disagree) and then compared between intervention and control groups at each time point. Exact logistic regression models were used to analyze the dichotomous outcomes including reported use of validated parent rated screening tools. Within each of the two groups, we also assessed the change in proportion of subjects who responded 'agree' at each of the two post-intervention time points from baseline. We again used exact logistic regression model to compare the proportions of subjects who responded 'agree' at 12- and 24-month post-intervention with the proportions of subjects who responded 'agree' at baseline. This study was reviewed and approved by Indiana University Office of Research Administration.

\section{Results}

The number of respondents for each survey administration was as follows: 45 at baseline, 39 at 12 months and 42 at 24 months. The response rates for the surveys were $100 \%$ at baseline and 12 months and $95 \%$ at 24 months. Primary specialty was the only characteristic that varied significantly between intervention and control groups, with pediatrics making up more of the control group. All other physician characteristics were not significantly different between the intervention and control group respondents at baseline, 12 or 24 months (data not shown for 12 months or 24 months). See - Table 1 for sample characteristics at baseline.

Respondents' knowledge of autism or the perception of role in diagnosis did not vary significantly between the control and intervention groups for any of the items at any time point. See - Table 2 for a summary of the median autism knowledge scores at each time point and by treatment group. At baseline, physicians in both groups reported similar rates in the routine use of parent-rated screening instruments (for example, the Modified Checklist for Autism in Toddlers or the M-CHAT) as part of the assessment of autism (47\% for intervention group vs. $42 \%$ for the control group). At 12 months, the rate of use of a parent-rated screening instrument increased for the intervention group to $79 \%$, while the rate for the control group remained essentially unchanged (46\%). The change for the intervention group was not statistically significant based on the exact logistic regression analysis $(\mathrm{p}=0.085)$ and group difference was also not statistically significant $(\mathrm{p}=0.057)$. At 24 months, the difference between the control and intervention group was significant $(\mathrm{p}=0.008$, $88 \%$ for the intervention group vs. $42 \%$ for the control group) and the change for the intervention group was significantly different from baseline $(\mathrm{p}=0.023)$ ( $\$$ Figure 3$)$. The control group did not exhibit a statistically significant change in the use of parent-rated screening instruments throughout the duration of the study.

At 12 and 24 months post-ASD module implementation, a majority of physicians (77\% of physicians in intervention group vs. $66 \%$ of physicians in control group) reported challenges associated with identifying resources in the community for further work-up and specialty treatment. 


\section{Discussion}

Our study shows that CHICA did not improve physicians' knowledge of or perceived role in ASD screening and diagnosis. Therefore, improved knowledge and attitudes cannot be the mechanism by which CHICA improved screening. Even though the intervention group reported increased use of a parent-rated ASD screening tool, specifically the M-CHAT, the control group's implementation of a similar tool remained unchanged. Our finding that clinics without CHICA were unable to implement ASD screening consistently despite widespread public health efforts at the community level to improve physician awareness and empower practices to implement universal screening for ASD emphasizes that publication and promotion of guidelines is often insufficient to change practice. Prior to the study, we did not assume any particular survey knowledge item would be changed by the ASD module given our hypothesis that exposure to the automated process of surveillance, screening and prompting of physicians would capitalize on the "teachable moment" that is often used at the point of care and heavily relied upon to train physicians at all points in their career.

However, our study highlights the fact that the use of health information technology, such as a CDSS, improves adherence to recommended clinical practices by integrating clinical care guidelines into clinical workflow. We found that CHICA increased rates of autism screening; this is consistent with previous work on the CDSS in medical settings, especially for preventive care [28-31]. This study adds to previous work by our group showing that health information technology greatly facilitates physicians' abilities to adhere to clinical care guidelines into busy pediatric practices $[13-16,23$, 32, 33]. Moreover, CHICA has characteristics of other successful CDSS in that it promotes routine screening and fits into the clinical workflow $[34,35]$.

Approaches aimed solely at improving physician knowledge are limited in their effectiveness in promoting actual change in physician practice. Continuing medical education is the traditional modality that is often used to improve physician knowledge, with the ultimate goal of changing physician behavior. However, passive approaches are generally not effective or sufficient enough to change clinical practice [36-39]. Evidence shows no one single strategy of all available approaches for transferring evidence-based medicine into "real world" practice is superior; [40] however those that incorporate reminder systems, academic detailing and multiple interventions are relatively strong [41]. However, based on responses at the 12 and 24 month time points, there were no significant differences in the perceived role of the primary care physician with respect to various aspects of chronic care management, including ongoing care coordination delivered in the medical home. This suggests that changes in the system, in this case through automation, were the key to making a change in physician behavior that they were otherwise ready to make. Given these results, one might wonder if increased screening had a significant effect on patient outcomes. The larger RCT examining the effect of the CHICA autism module has recently been completed and final analysis of the data, including family interviews about care received, are underway.

Our findings are consistent those reported by Carbone at al, 2010 that few physicians viewed themselves as direct providers of comprehensive ASD care, but more as advocates, referral sources and care coordinators [42]. In our study, physicians in both intervention and control clinics felt finding resources for further evaluation and treatment of ASD was challenging. Our findings support the need for multi-faceted interventions to improve not only physician detection of ASD in primary care, but systems-change that also improves access to community services that medical homes often rely upon to provide comprehensive, coordinated care to these families. Moreover, health information technology has the potential to facilitate the sharing of patient data housed in electronic medical records and make it available to various members of the interdisciplinary team. While there is value in supporting physicians during the actual patient encounter using a CDSS, continued work building and sustaining interdisciplinary collaboration and systems to ensure care coordination with community providers is critical in supporting the primary care medical home. Moreover, technological modifications to our existing CDSS can be done to facilitate these processes between the medical home and community providers. Other informatics work has been done using machine intelligence to aid in the rapid detection and clinical prioritization of children at risk for ASD [43-47]. Ongoing work that is aided by health information technology shows early promise to ensure families' needs are met in a timely manner. 
Certain limitations of our study should be acknowledged. Data are from surveys that asked physicians about their knowledge and perceived role in identification and management of ASDs. Surveys are subject to social desirability bias. We tried to limit this by keeping surveys de-identified at each time point to encourage honest answers from respondents. However, in doing so, we were unable to measure individual changes in knowledge and beliefs over time. Also, even though the surveys did not ask for direct personal identifying information, the number of providers surveyed and granularity of the questions answered could potentially unmask the anonymity of the respondents. Moreover, physicians' self-reported practices to measure changes in adherence to screening guidelines may be less reliable than measuring the rate of screening via medical record data. We are undertaking external validation as part of the larger RCT. This work is underway, and preliminary results confirm the physicians' reports. Also, the actual process of inputting and outputting data with scannable documents is not commonly used by other CDSSs. This limits the external validity of the technology. However, the CHICA system is currently in the process of moving to a paperless environment. Lastly, the number of survey respondents, particularly in the intervention group, is quite small. Furthermore, because individual respondents could not be tracked and there were changes to the physician population, these had to be treated as independent samples. The result is some loss in statistical power, but this is unlikely to threaten the validity of the results. We acknowledge we may not have had adequate sample size to draw the conclusion that this intervention did not lead to knowledge change.

\section{Conclusion}

Our CDSS improved physician-reported use of validated screening tools to identify children at-risk for ASD. A CDSS can improve clinical care, but the mechanism is not related to changes in knowledge or attitudes.

\section{CLINICAL RELEVANCE STATEMENT}

Implementation of a CDSS within a busy pediatric practice promotes adherence to clinical care guidelines but does not lead to changes in physician knowledge or attitudes towards autism spectrum disorders.

\section{CONFLICTS OF INTEREST}

The authors declare that they have no conflicts of interest in the research.

\section{HUMAN SUBJECTS PROTECTIONS}

The study was conducted in compliance with the World Medical Association Declaration of Helsinki on Ethical Principles for Medical Research Involving Human Subjects, and was reviewed by the Indiana University Institutional Review Board.

\section{ACKNOWLEDGEMENTS}

The authors wish to acknowledge the technical expertise and efforts of the individual members of the Child Health Improvement Research and Development Lab (CHIRDL) team, which provides programming and technical support for CHICA, the Pediatric Research Network (PResNet) at Indiana University for administering the Autism Practice Survey at the pediatric clinics with CHICA, specifically Amy Pottenger, Elaine Cuevas, Vickie Cater, Jaskaran Mahal and Kailie Stout. The authors wish to thank the clinic personnel who constantly help us evaluate and improve CHICA. This work was supported by grant number R01HS018453 from the Agency for Healthcare Research and Quality. 


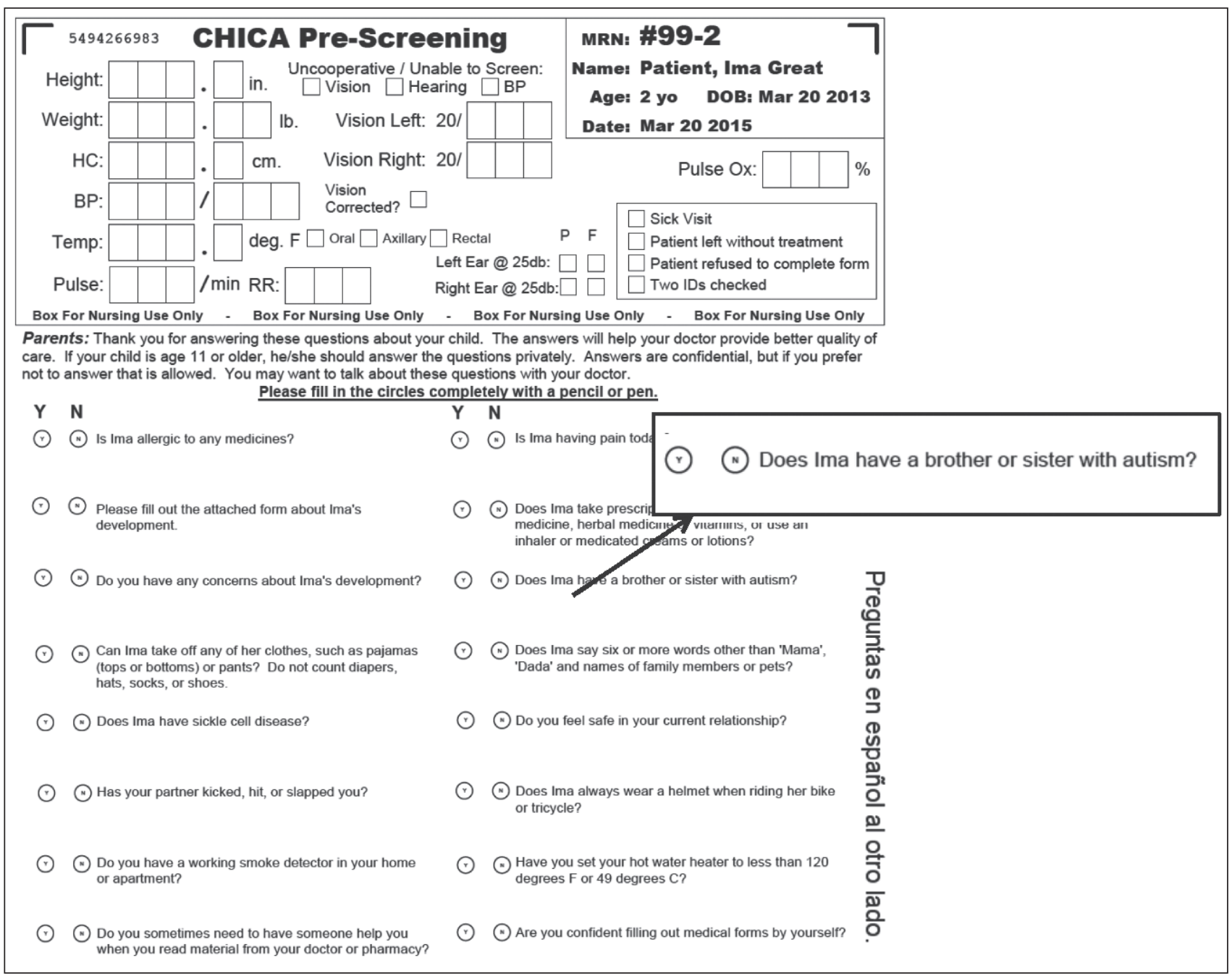

Fig. 1 Sample Pre-screener Form (PSF) with autism surveillance item shown in insert 


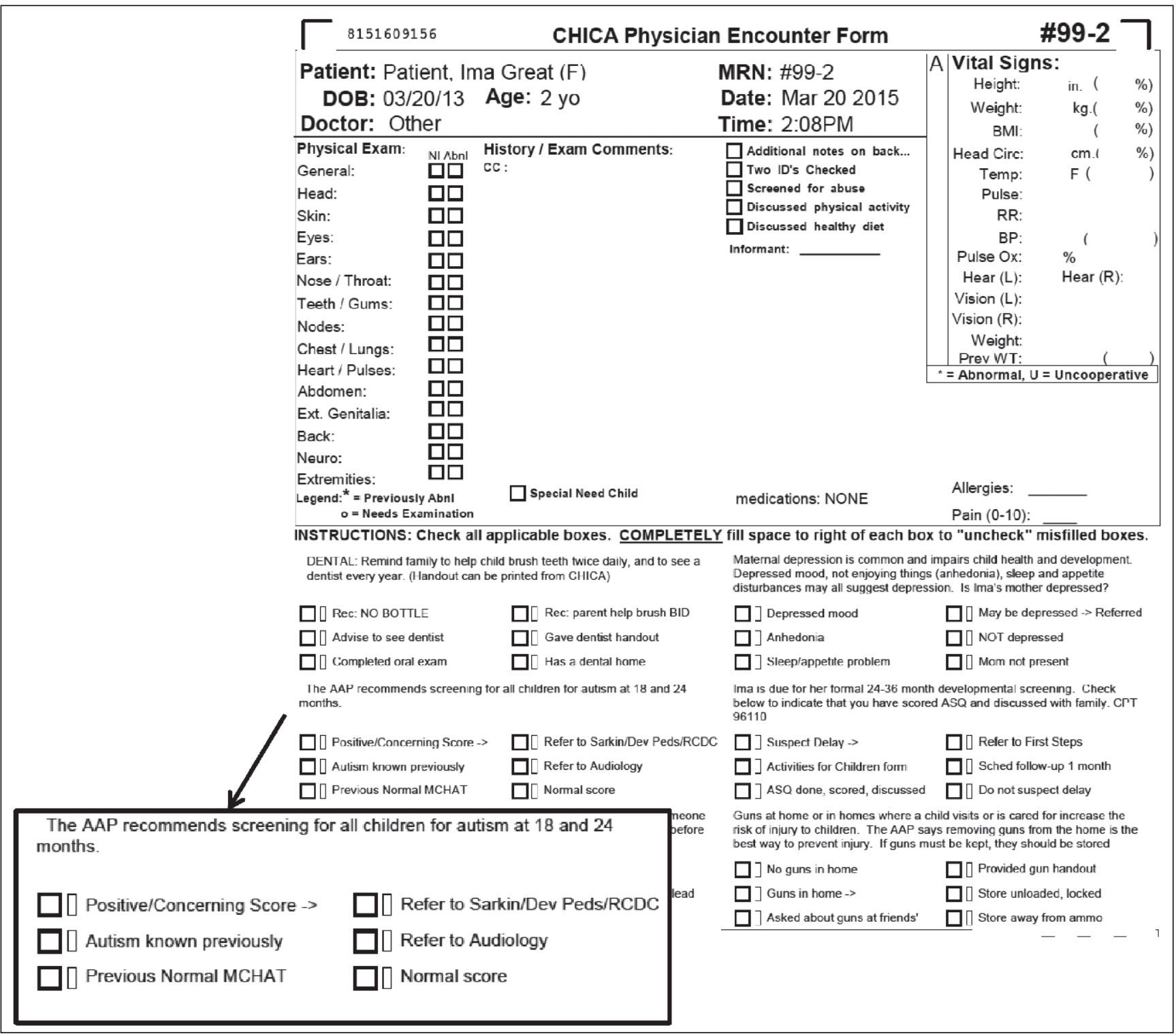

Fig. 2 Sample Physician Worksheet (PWS) with autism prompt shown in insert

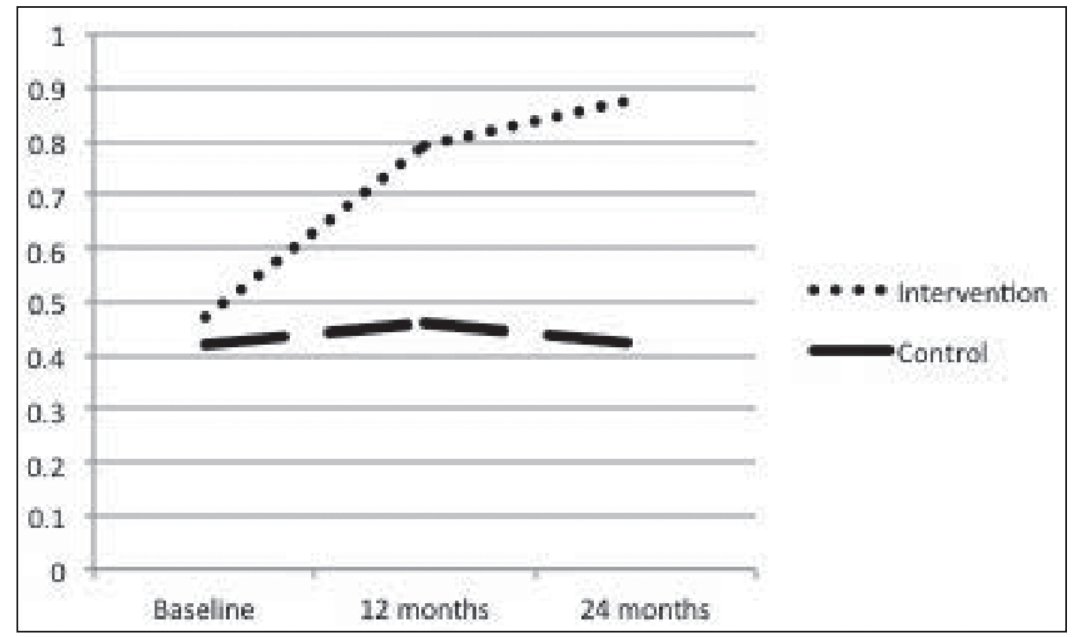

(C) Schattauer 2015
N.S. Bauer et al.: Computer decision support system regarding ASD
Fig. 3

Percentage of physicians reporting routine use of parent-rated screening instrument for autism assessment 
Table 1 Baseline Physician Characteristics

\begin{tabular}{|c|c|c|}
\hline & Intervention $\mathrm{N}(\%)$ & Control N(\%) \\
\hline Female gender & $9(56)$ & $18(62)$ \\
\hline \multicolumn{3}{|l|}{ Years in practice (post-residency) } \\
\hline $1-5$ years & $5(31)$ & $5(17)$ \\
\hline $6-10$ years & $2(12)$ & $5(17)$ \\
\hline $11-20$ years & $4(25)$ & $4(14)$ \\
\hline $20+$ years & $2(13)$ & $2(7)$ \\
\hline Resident & $3(19)$ & $12(41)$ \\
\hline \multicolumn{3}{|l|}{ Primary Speciality } \\
\hline Pediatrics & $7(44)$ & $25(86)$ \\
\hline Internal Medicine/Pediatrics & $3(19)$ & $2(7)$ \\
\hline Other & $5(31)$ & $1(3)$ \\
\hline \multicolumn{3}{|c|}{ Completed residency/training in the following fields: } \\
\hline Developmental-Behavioral Pediatrics & $0(0)$ & $0(0)$ \\
\hline Psychiatry/Child Psychiatry & $0(0)$ & $1(3)$ \\
\hline Other & $2(13)$ & $3(10)$ \\
\hline Not Applicable & $9(56)$ & $13(45)$ \\
\hline \multicolumn{3}{|c|}{ On average, how many children 18 years or younger seen per week } \\
\hline $1-25$ & $8(50)$ & $14(48)$ \\
\hline $26-50$ & $6(38)$ & $5(17)$ \\
\hline $51-75$ & $1(6)$ & $3(10)$ \\
\hline $76-100$ & $1(6)$ & $4(14)$ \\
\hline$>100$ & $0(0)$ & $2(7)$ \\
\hline \multicolumn{3}{|l|}{ Average weekly time in clinic } \\
\hline Full time & $4(25)$ & 4 (14) \\
\hline Part-time & $11(69)$ & $23(79)$ \\
\hline
\end{tabular}

*totals may not equal $100 \%$ due to missing or skipped items

BOLD results indicate significant difference by the Fishers Exact test at the $p \leq 0.05$ level 


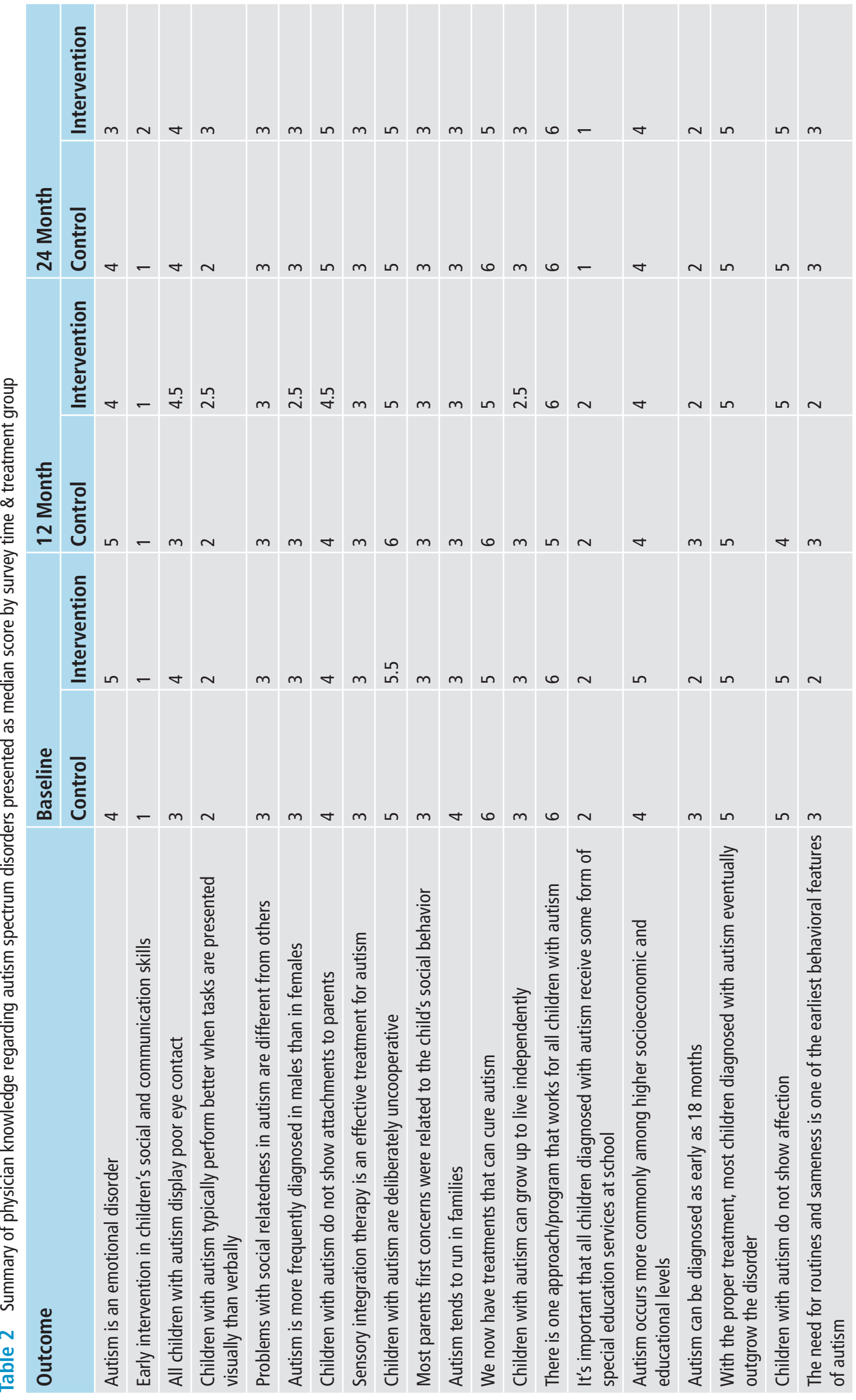




\section{References}

1. Baio J. Prevalence of Autism Spectrum Disorders-Autism and Developmental Disabilities Monitoring Network, 14 Sites, United States, 2008. MMWR Surveill Summ 2012; 61(SS03): 1-19.

2. Dosreis S, Weiner CL, Johnson L, Newschaffer CJ. Autism spectrum disorder screening and management practices among general pediatric providers. J Dev Behav Pediatr 2006; 27(2 Suppl): S88-94.

3. Osborne LA, Reed P. Parents' perceptions of communication with professionals during the diagnosis of autism. Autism 2008; 12(3): 309-324.

4. Shattuck PT, Durkin M, Maenner M, Newschaffer C, Mandell DS, Wiggins L, Lee LC, Rice C, Giarelli E, Kirby R, Baio J, Pinto-Martin J, Cuniff C. Timing of identification among children with an autism spectrum disorder: findings from a population-based surveillance study. J Am Acad Child Adolesc Psychiatry 2009; 48(5): 474-483.

5. American Academy of Pediatrics: The pediatrician's role in the diagnosis and management of autistic spectrum disorder in children. Pediatrics 2001; 107(5): 1221-1226.

6. Johnson CP, Myers SM. Identification and evaluation of children with autism spectrum disorders. Pediatrics 2007; 120(5): 1183-1215.

7. Robins DL. Screening for autism spectrum disorders in primary care settings. Autism 2008; 12(5): 537-556.

8. Blumenthal D, Causino N, Chang YC, Culpepper L, Marder W, Saglam D, Stafford R, Starfield B. The duration of ambulatory visits to physicians. The Journal of family practice 1999; 48(4): 264-271.

9. Belamarich PF, Gandica R, Stein RE, Racine AD. Drowning in a sea of advice: pediatricians and American Academy of Pediatrics policy statements. Pediatrics 2006; 118(4): e964-978.

10. Allen SG, Berry AD, Brewster JA, Chalasani RK, Mack PK. Enhancing developmentally oriented primary care: an Illinois initiative to increase developmental screening in medical homes. Pediatrics 2010; 126 ( Suppl 3): S160-164.

11.Zuckerman KE, Mattox K, Donelan K, Batbayar O, Baghaee A, Bethell C. Pediatrician identification of Latino children at risk for autism spectrum disorder. Pediatrics 2013; 132(3): 445-453.

12. Buntin MB, Burke MF, Hoaglin MC, Blumenthal D. The benefits of health information technology: a review of the recent literature shows predominantly positive results. Health affairs 2011; 30(3): 464-471.

13. Carroll AE, Bauer NS, Dugan TM, Anand V, Saha C, Downs SM. Use of a Computerized Decision Aid for Developmental Surveillance and Screening: A Randomized Clinical Trial. JAMA Pediatr 2014.

14. Carroll AE, Biondich P, Anand V, Dugan TM, Downs SM. A randomized controlled trial of screening for maternal depression with a clinical decision support system. Journal of the American Medical Informatics Association: JAMIA. 2012.

15. Carroll AE, Biondich PG, Anand V, Dugan TM, Sheley ME, Xu SZ, Downs SM. Targeted screening for pediatric conditions with the CHICA system. Journal of the American Medical Informatics Association: JAMIA 2011; 18(4): 485-490.

16. Anand V, Carroll AE, Downs SM. Automated primary care screening in pediatric waiting rooms. Pediatrics 2012; 129(5): e1275-1281.

17.Downs SM, Zhu V, Anand V, Biondich PG, Carroll AE. The CHICA smoking cessation system. AMIA Annu Symp Proc 2008: 166-170.

18. Anand V, Biondich PG, Liu G, Rosenman M, Downs SM. Child Health Improvement through Computer Automation: the CHICA system. Stud Health Technol Inform 2004; 107(1): 187-191.

19.Downs SM, Biondich PG, Anand V, Zore M, Carroll AE. Using Arden Syntax and adaptive turnaround documents to evaluate clinical guidelines. AMIA Annu Symp Proc 2006: 214-218.

20.Downs SM, Carroll AE, Anand V, Biondich PG. Human and system errors, using adaptive turnaround documents to capture data in a busy practice. AMIA Annu Symp Proc 2005: 211-215.

21. Downs SM, Uner H. Expected value prioritization of prompts and reminders. Proceedings / AMIA Annual Symposium AMIA Symposium 2002: 215-219.

22. McDonald CJ, Overhage JM, Tierney WM, Dexter PR, Martin DK, Suico JG, Zafar A, Schadow G, Blevins L, Glazener T, Meeks-Johnson J, Lemmon L, Warvel J, Porterfield B, Cassidy P, Lindbergh D, Belsito A, Tucker M, Williams B, Wodniak C. The Regenstrief Medical Record System: a quarter century experience. International journal of medical informatics 1999; 54(3): 225-253.

23. Bauer NS, Sturm LA, Carroll AE, Downs SM. Computer decision support to improve autism screening and care in community pediatric clinics. Infants \& Young Children 2013; 26(4): 306-317.

24. Robins DL, Casagrande K, Barton M, Chen CM, Dumont-Mathieu T, Fein D. Validation of the Modified Checklist for Autism in Toddlers, Revised With Follow-up (M-CHAT-R/F). Pediatrics 2014; 133(1): 37-45. 
25. Robins DL, Dumont-Mathieu TM. Early screening for autism spectrum disorders: update on the modified checklist for autism in toddlers and other measures. J Dev Behav Pediatr 2006; 27(2 Suppl): S111-119.

26. Chlebowski C, Robins DL, Barton ML, Fein D. Large-scale use of the modified checklist for autism in lowrisk toddlers. Pediatrics 2013; 131(4): e1121-1127.

27.Stone WL. Cross-disciplinary perspectives on autism. J Pediatr Psychol 1987; 12(4): 615-630.

28. Steele AW, Eisert S, Davidson A, Sandison T, Lyons P, Garrett N, Gabow P, Ortiz E. Using computerized clinical decision support for latent tuberculosis infection screening. American journal of preventive medicine 2005; 28(3): 281-284.

29. Thomas KW, Dayton CS, Peterson MW. Evaluation of internet-based clinical decision support systems. Journal of medical Internet research 1999; 1(2): E6.

30. Nagykaldi Z, Mold JW. The role of health information technology in the translation of research into practice: an Oklahoma Physicians Resource/Research Network (OKPRN) study. J Am Board Fam Med 2007; 20(2): 188-195.

31. Hunt DL, Haynes RB, Hanna SE, Smith K. Effects of computer-based clinical decision support systems on physician performance and patient outcomes: a systematic review. JAMA : the journal of the American Medical Association 1998; 280(15): 1339-1346.

32. Carroll AE, Bauer NS, Dugan TM, Anand V, Saha C, Downs SM. Use of a computerized decision aid for ADHD diagnosis: a randomized controlled trial. Pediatrics 2013; 132(3): e623-629.

33. Bauer NS, Carroll AE, Downs SM. Understanding the acceptability of a computer decision support system in pediatric primary care. Journal of the American Medical Informatics Association: JAMIA 2013.

34. Bates DW, Kuperman GJ, Wang S, Gandhi T, Kittler A, Volk L, Spurr C, Khorasani R, Tanasijevic M, Middleton B. Ten commandments for effective clinical decision support: making the practice of evidencebased medicine a reality. Journal of the American Medical Informatics Association: JAMIA 2003; 10(6): 523-530.

35. Sim I, Gorman P, Greenes RA, Haynes RB, Kaplan B, Lehmann H, Tang PC. Clinical decision support systems for the practice of evidence-based medicine. Journal of the American Medical Informatics Association: JAMIA 2001; 8(6): 527-534.

36. Parochka J, Paprockas K. A continuing medical education lecture and workshop, physician behavior, and barriers to change. J Contin Educ Health Prof. 2001; 21(2): 110-116.

37. Davis D, O’Brien MA, Freemantle N, Wolf FM, Mazmanian P, Taylor-Vaisey A. Impact of formal continuing medical education: do conferences, workshops, rounds, and other traditional continuing education activities change physician behavior or health care outcomes? JAMA : the journal of the American Medical Association 1999; 282(9):867-874.

38. Grimshaw JM, Shirran L, Thomas R, Mowatt G, Fraser C, Bero L, Grilli R, Harvey E, Oxman A, O’Brien MA. Changing provider behavior: an overview of systematic reviews of interventions. Med Care 2001; 39(8 Suppl 2): II2-45.

39. Oxman AD, Thomson MA, Davis DA, Haynes RB. No magic bullets: a systematic review of 102 trials of interventions to improve professional practice. $\mathrm{CMAJ}$ : Canadian Medical Association journal = journal de l'Association medicale canadienne 1995; 153(10): 1423-1431.

40. Grol R, Grimshaw J. From best evidence to best practice: effective implementation of change in patients' care. Lancet 2003; 362(9391): 1225-1230.

41.Davis DA, Taylor-Vaisey A. Translating guidelines into practice. A systematic review of theoretic concepts, practical experience and research evidence in the adoption of clinical practice guidelines. CMAJ : Canadian Medical Association journal = journal de l'Association medicale canadienne 1997; 157(4): 408-416.

42. Carbone PS, Behl DD, Azor V, Murphy NA. The medical home for children with autism spectrum disorders: parent and pediatrician perspectives. J Autism Dev Disord 2010; 40(3): 317-324.

43. Kosmicki JA, Sochat V, Duda M, Wall DP. Searching for a minimal set of behaviors for autism detection through feature selection-based machine learning. Translational psychiatry 2015; 5: e514.

44. Fusaro VA, Daniels J, Duda M, DeLuca TF, D’Angelo O, Tamburello J, Maniscalco J, Wall DP. The potential of accelerating early detection of autism through content analysis of YouTube videos. PLOS one 2014; 9(4): e93533.

45. Wall DP, Dally R, Luyster R, Jung JY, Deluca TF. Use of artificial intelligence to shorten the behavioral diagnosis of autism. PLOS one 2012; 7(8): e43855.

46. Wall DP, Kosmicki J, Deluca TF, Harstad E, Fusaro VA. Use of machine learning to shorten observationbased screening and diagnosis of autism. Translational psychiatry 2012; 2: e100.

47.Duda M, Kosmicki JA, Wall DP. Testing the accuracy of an observation-based classifier for rapid detection of autism risk. Translational psychiatry 2014; 4: e424. 